\title{
Incidence and impact of pain conditions and comorbid illnesses
}

\author{
Jessica A Davis \\ Rebecca L Robinson \\ Trong Kim Le \\ Jin Xie
}

Lilly Research Laboratories, Eli Lilly and Company, Indianapolis, IN, USA

Correspondence: Jessica A Davis Eli Lilly and Company, Lilly Corporate Center, Drop Code I542, Indianapolis, IN 46285, USA

$\mathrm{Tel}+\mathrm{I} 3176559510$

Fax +I 3172766026

Email davisje@lilly.com

\author{
This article was published in the following Dove Press journal: \\ Journal of Pain Research \\ II October 2011 \\ Number of times this article has been viewed
}

Background: Individuals with pain often present with more than one painful condition. The purpose of this study was to characterize the rates of comorbidity, pain medication use, and health care costs for 23 selected pain conditions in a large health plan using administrative claims data from 2005 to 2007.

Methods: Eligible patients included 1,211,483 adults with at least one pain condition during the one-year study period. Pain condition cohorts were classified based on the first diagnosis present in the claims during the study period.

Results: Musculoskeletal pain conditions were among the most prevalent cohorts including low back pain, osteoarthritis, and fibromyalgia. Cancer pain was the least prevalent cohort. Conditions with the lowest illness severity included migraine and painful bladder syndrome cohorts, while cohorts with diabetic neuropathy, human immunodeficiency virus (HIV)-associated pain, and cancer pain were the most severe. Across cohorts, the mean number of comorbid pain conditions ranged from 1.39 (for cancer pain and migraine) to 2.65 (for multiple sclerosis pain). High rates of mental health conditions were found in cohorts with HIV-associated pain and multiple sclerosis pain (42.59\% and 34.78\%) and were lowest among cohorts with rheumatoid arthritis and psoriatic arthropathy $(12.73 \%$ and $13.31 \%)$, respectively. Rates of sleep disorders ranged from $5.47 \%$ (for painful bladder syndrome) to $11.59 \%$ (for multiple sclerosis pain). Overall, patients averaged 3.53 unique pain medications during the study period. Considerable annual total health care costs were observed in the cancer pain cohort and the lowest costs were observed in the postherpetic neuropathy, surgically-induced pain, migraine, and irritable bowel syndrome cohorts. Costs attributed to pain were highest among the multiple sclerosis, HIV, and cancer pain cohorts. The highest pharmaceutical costs were observed in the HIV cohort.

Conclusion: These findings underscore the heterogeneity of patients with pain in terms of burden of illness, costs to the health care system, and the complexity of commonly co-occurring disorders.

Keywords: retrospective, health care costs, pain medication use, chronic pain, neuropathic pain

\section{Introduction}

Pain is the leading reason for patients seeking medical care ${ }^{1}$ and is one of the most disabling, burdensome, and costly conditions in the US. Overall, pain care/treatment and lost productivity costs US\$635 billion per year. ${ }^{2}$ One study estimated that common pain conditions result in an additional estimated $\$ 61$ billion annual loss in productivity among active US workers (US dollars for 2002). ${ }^{3}$ An increased rate of chronic pain has been associated with being female, older, and leaving the workforce earlier through retirement or sick leave. Females aged 50-64 years who retired early 
were estimated to have a $91.1 \%$ prevalence of chronic pain. ${ }^{4}$ Given the aging US population and the unsustainably increasing percentage of the US gross domestic product devoted to health care, there is a clear and imminent need for valid health care economic evaluation data to establish health care funding priorities, including for chronic pain treatment modalities.

Chronic pain accompanies a variety of diseases and occurs across the entire life span. Individuals with multiple chronic conditions have been found to have higher health care expenditures, including some avoidable medical care costs. ${ }^{5}$ To improve the research and management of pain, greater understanding is needed on the heterogeneity of patients with pain, yet epidemiological and clinical research traditionally imposes constraints that prevent us from assessing the holistic view of a patient with pain. Either studies look broadly at the severity or impact of pain in global terms or, if a condition is examined, pain related to other conditions is often excluded (eg, all chronic pain).

Several studies have identified the strong association between the presence of chronic pain and mental health conditions, such as depression, ${ }^{6-9}$ anxiety, ${ }^{10}$ or mental health in general. ${ }^{4}$ For example, the association between depression and chronic pain has been well studied. ${ }^{7}$ In a systematic literature review, $65 \%$ of patients with depression experienced pain. ${ }^{7}$ This review concluded that patients with moderate to severe pain were more likely to experience greater symptoms of depression, nonresponsiveness to treatment for depression, and worse depression outcomes, such as lower quality of life and decreased work function. Other studies found an increase in health care resource utilization and costs associated with patients with depression and pain relative to patients with either condition alone. ${ }^{9,11}$ Results from a survey of 17 countries found that, as the number of pain complaints increased, so did the likelihood of mood or anxiety disorders. ${ }^{12}$ Depression has been found, in numerous studies, to co-occur with spinal cord injury and many other conditions, including osteoarthritis and diabetic neuropathy. ${ }^{13}$

Pain has also been associated with sleep disorders ${ }^{14}$ and complex chronic illnesses such as heart failure and diabetes. ${ }^{15}$ Osteoarthritis has been observed to coexist with other conditions in over $90 \%$ of patients, these conditions include cardiovascular, respiratory, gastrointestinal, urogenital, endocrine, metabolic, and neurological diseases, as well as diseases of the ear, eye, throat, and larynx. ${ }^{16}$ Neuropathic pain conditions have also been found to occur with sleep disturbances, as well as depression and anxiety. ${ }^{17}$
Less is known about the rates of multiple pain diagnoses. The presence of pain is believed to cause individuals to be more susceptible to pain in other areas. ${ }^{18}$ This may be explained by central sensitization theory, which purports cells of neurons change following a prolonged pain stimulus. ${ }^{18}$ These changes increase the responsiveness of the neurons and lowered pain thresholds following repeated stimulation. ${ }^{18}$ Research to date has been limited to specific pain conditions and other pain comorbidities, and headache and migraine, and the pain comorbidities that occur with those specific conditions have been the focus of the available literature..$^{19,20}$

Because patients with pain attributed to various conditions may be quite diverse across demographic and clinical experiences, we aimed at looking holistically at the comorbidities associated with each cohort of patients. Therefore, the purpose of this study was to characterize the rates of comorbidity, pain medication use, and health care costs for selected pain conditions in a large health plan using administrative health claims data. We identified the most prevalent types of pain conditions, as well as pain medication use and direct health care costs associated with selected pain conditions. This study also allowed us to compare distinct pain categories and individual pain diagnoses descriptively within a single data source.

\section{Materials and methods \\ Data source}

Thomson Reuters' MarketScan United States Commercial and Medicare Supplemental retrospective claims databases covering the years 2005-2007 were used to address the study objectives. These databases contain national, employerbased insurance claims for active and retired employees and their dependants. While the databases are not considered to be nationally representative, the data do include those in various sociodemographic groups and geographies across the US. Data consist of person-specific information on enrollment, medical, and pharmacy claims. Enrollment data included monthly enrollment status and demographic information such as age and gender. Age was assessed as both a continuous and dichotomous variable in order to examine the subpopulation that was 65 years and older. Medical claims provided facility and provider specialty categories, diagnosis codes based on the International Classification of Diseases, 9th Edition (ICD-9), provider payments, and dates of service. Prescription drug claims included National Drug Codes, number of days supplied, prescription fill dates, and payments. Line of therapy was defined by the order in which medications were prescribed subsequent to the initial 
diagnosis date. All data are de-identified but linkable with encrypted patient identifiers to remain compliant with the Health Insurance Portability and Accountability Act.

\section{Study sample and cohorts}

Patients met the study inclusion criteria if they were diagnosed with at least one of the selected pain conditions between January 1, 2006 and December 31, 2006 (the index period) and had two years of continuous pharmaceutical and medical benefit enrollment between January 1, 2005 and December 31,2007. This allowed for one year prior to and one year following the first pain diagnosis during the index period (index diagnosis). Patients were 18 years of age or older at the time of the index diagnosis. The final sample included 1,211,483 patients with pain conditions.

To quantify the percentage of patients with unique pain types, patients were classified into 23 individual pain conditions based on the ICD-9 code for the index diagnosis. These include pain conditions that are considered chronic (typically, lasting longer than three months). If more than one selected pain condition was present during the first claim, patients were categorized according to the primary diagnosis. If there was more than one primary diagnosis, patients were placed into the cohorts of primary interest for this study in the order in which the indications appear in Table 1. Table 1 depicts the counts and ICD-9 definitions for the 23 specific pain conditions.

To address the objective of characterizing the rates of comorbidity for 23 selected pain cohorts, the Charlson Comorbidity Index and the Chronic Disease Score variables were constructed. The Charlson Comorbidity Index assesses comorbidity level by taking into account both the number and severity of diagnoses available from the medical records. A higher score has been validated to be predictive of outcomes such as function, hospital length of stay, and mortality rates. The Chronic Disease Score uses a variation in the algorithm to measure severity of comorbidity measures of overall sickness.

The presence of comorbidities in each of the 23 pain cohorts was assessed for other concurrent pain conditions, mental health, and sleep disorders. To be considered comorbid, the co-occurring condition defined through ICD-9 claims

Table I Pain condition cohorts: definition and sample size

\begin{tabular}{|c|c|c|c|}
\hline Pain cohort & ICD-9 definitions & $\mathbf{n}$ & $\%$ \\
\hline Diabetic neuropathy & $250.6,357.2$ & 37,133 & $3.07 \%$ \\
\hline Postherpetic neuropathy & $053.10,053.11,053.12,053.13,053.14,053.19$ & 3551 & $0.29 \%$ \\
\hline Trigeminal neuralgia & 350.1 & 3869 & $0.32 \%$ \\
\hline HIV-associated pain & $\begin{array}{l}\text { HIV }(042,079.53,795.71, \text { V08) and other chronic pain }(338.29) \text {, } \\
\text { chronic pain syndrome }(338.4) \text { or generalized pain }(780.96)\end{array}$ & 371 & $0.03 \%$ \\
\hline Stroke-associated pain & Stroke $(430-434.9,436-437.9)$ and central pain syndrome (338.0) & 3087 & $0.25 \%$ \\
\hline Lumbar radiculopathy & 724.4 & 56,358 & $4.65 \%$ \\
\hline Complex regional pain syndrome & 337.2 & 1808 & $0.15 \%$ \\
\hline Spinal cord injury & $\begin{array}{l}\text { Spinal cord injury without evidence of spinal bone injury }(952) \\
\text { and } 338.29,338.4,780.96\end{array}$ & 331 & $0.03 \%$ \\
\hline Surgically-induced pain & $\begin{array}{l}\text { Other acute postoperative pain }(338.18) \text {, other chronic postoperative pain } \\
(338.28)\end{array}$ & 1478 & $0.12 \%$ \\
\hline Phantom limb & 353.6 & 205 & $0.02 \%$ \\
\hline Cervical radiculopathy & Cervical radiculitis (723.4) & 40,844 & $3.37 \%$ \\
\hline Multiple sclerosis-associated pain & 340 and central pain syndrome $(338.0)$ & 647 & $0.05 \%$ \\
\hline Fibromyalgia & 729.1 & 75,570 & $6.24 \%$ \\
\hline Osteoarthritis & $\begin{array}{l}715.0,7|5.1,7| 5.2,7|5.8,7| 5.9,721.0,721.1,721.2,721.3 \\
721.41,721.42\end{array}$ & 365,086 & $30.14 \%$ \\
\hline Low back pain & $722.83,724.02,724.2,724.5,724.8$ & 424,410 & $35.03 \%$ \\
\hline Migraine & $346.0,346.1,346.2,346.8,346.9$ & 92,943 & $7.67 \%$ \\
\hline Rheumatoid arthritis & 7|4.0, 7|4.|, 7|4.2, 7|4.30, 7|4.3।, 7|4.32, 7|4.33, 7|4.4, 7|4.8। & 40,362 & $3.33 \%$ \\
\hline Ankylosing spondylitis & $720.0,720.1,720.2,720.81,720.89$ & 10,050 & $0.83 \%$ \\
\hline Psoriatic arthropathy & 696 & 4795 & $0.40 \%$ \\
\hline Cancer pain & 338.3 & 28 & $0.00 \%$ \\
\hline Irritable bowel syndrome & 564.1 & 40,025 & $3.30 \%$ \\
\hline Painful bladder syndrome & $\begin{array}{l}\text { Urinary frequency }(788.4 \mathrm{I}) \text { with other specified symptoms } \\
\text { associated with female genital organs }(625.8) \text { or unspecified } \\
\text { symptoms associated with female genital organs (625.9) }\end{array}$ & 2870 & $0.24 \%$ \\
\hline Interstitial cystitis & 595.1 & 5662 & $0.47 \%$ \\
\hline
\end{tabular}


had to be present during the one-year follow-up period. Pain comorbidities were defined using the same 23 conditions, but occurring after the index pain diagnosis. Mental health conditions were categorized into any mental health condition, as well as categories of major depressive disorder (296.2, 296.3), other depressive symptoms (311), anxiety (300.0, 300.1, 300.2, 300.3-300.7, 300.8), and other psychiatric conditions $(293,294,297,298,299,316,780.02,780.1$, $780.50,780.52,780.54-780.56,780.58,780.59)$. The rates of any mental health condition and the mean number of mental health conditions were assessed. Any mental health condition included patients with major depressive disorder, other depressive symptoms, anxiety, other psychiatric conditions, and a host of other conditions including dementias (290), schizophrenic disorders (295), personality disorders (301), sexual and gender identity disorders (302), physiological malfunction arising from mental factors (306.7-306.9), special symptoms or syndromes, not elsewhere classified (307.3, 307.4, 307.5, 307.6, 307.7, 307.80, 307.89, 307.9), acute reaction to stress (308), adjustment reaction (309), specific nonpsychotic mental disorders due to brain damage (310), disturbance of conduct not elsewhere classified (312), disturbance of emotions specific to childhood and adolescence (313), hyperkinetic syndrome of childhood (314), specific delays in development (315), mental retardation $(317,318$, 319), organic sleep disorders (327.0-327.1), chromosomal anomalies (758.0-758.2, 758.3), other symbolic dysfunction (784.6), senility without mention of psychosis (797), nervousness (799.2), and observation for suspected mental condition (v71.01, v71.02, v71.09). Comorbid sleep conditions included specific disorders of sleep of nonorganic origin (307.4), sleep disturbances (780.5), organic sleep disorders (327), cataplexy and narcolepsy (347), and lack of adequate sleep (v69.4).

Descriptors of pain medication use included the number of unique pain medications prescribed, line of therapy, and length of therapy. Pain medications were defined as antidepressants (selective serotonin reuptake inhibitors, serotonin norepinephrine reuptake inhibitors, tricyclic antidepressants, others), anticonvulsants, analgesics/antipyretics not elsewhere classified, anxiolytic/sedative/hypnotic, benzodiazepines, cyclo-oxygenase-2 inhibitors, muscle relaxants, nonsteroidal anti-inflammatory drugs, proton pump inhibitors, strong opioids, and weak opioids. The order that the medication class was prescribed to new pain patients was examined as a proxy for line of therapy. Length of therapy was calculated as sum of days supply over the one-year study period.
The median total health care costs were also presented for each pain cohort. This was calculated using actual cash payments by the insurer for all costs related to the cost components of pharmacy, emergency department, and inpatient and outpatient costs. These costs do not include copayments or deductibles paid by the insured. The median costs were also calculated and reported for each of these cost components. Further delineation was made as to whether these costs were associated with pain-related costs. Pain costs were defined as costs that were incurred during the same claim as any of the diagnoses associated with pain (listed in Table 1), and not only pain costs related to the index diagnosis (ie, the pain cohort of interest).

\section{Results \\ Patient characteristics}

Of the 23 specific pain conditions, low back pain (35.03\%), osteoarthritis (30.14\%), migraine (7.67\%), and fibromyalgia (6.24\%) occurred most frequently. The least commonly reported condition was cancer pain, which included only 28 patients $(0.00 \%)$. Women comprised the majority of each cohort in all but five conditions ( $\%$ female), ie, phantom limb (28.78\%), diabetic neuropathy (47.14\%), human immunodeficiency virus (HIV)-associated pain (48.52\%), psoriatic arthropathy (49.49\%), and cancer pain $(50.00 \%)$, as shown in Table 2 . Conditions almost exclusively observed in women included painful bladder syndrome $(98.29 \%)$, interstitial cystitis $(88.2 \%)$, multiple sclerosis-associated neuropathic pain $(81.30 \%)$, and migraine (81.19\%).

Age of patients (mean \pm standard deviation) in the specific pain cohorts ranged from $42.9 \pm 12.78$ years for migraine to $65.32 \pm 15.74$ years for stroke-associated neuropathic pain. There were differences observed in the prevalence of pain conditions in the 65 years and older age group. Some conditions were significantly less prevalent in the aged population, such as HIV-associated pain $(0.27 \%)$, multiple sclerosis-associated pain (5.26\%), complex regional pain syndrome $(10.51 \%)$, migraine $(4.25 \%)$, and painful bladder syndrome $(8.08 \%)$. Conversely, there were other pain conditions that had a higher prevalence in those aged 65 years and older, such as postherpetic neuropathy $(53.34 \%)$ and stroke-associated pain (52.22\%). Variations across specific pain conditions were also found across indicators of severity of illness using the Charlson Comorbidity Index and Chronic Disease Score. Across both indicators, migraine and painful bladder symptoms, cohorts had the least severe scores. Diabetic neuropathy, HIV-associated 
Table 2 Demographic characteristics of pain condition cohorts

\begin{tabular}{|c|c|c|c|c|c|}
\hline Characteristics & $\begin{array}{l}\text { Gender, \% } \\
\text { female }\end{array}$ & $\begin{array}{l}\text { Age, } \\
\text { mean (SD) }\end{array}$ & $\begin{array}{l}\text { Age } 65 \text { years } \\
\text { or older, \% }\end{array}$ & $\begin{array}{l}\mathrm{CCl}^{\mathrm{a}} \\
\text { mean (SD) }\end{array}$ & $\begin{array}{l}\text { CDS }^{b} \\
\text { mean (SD) }\end{array}$ \\
\hline Diabetic neuropathy $(n=37,133)$ & 47.14 & $62.44(12.57)$ & 41.7 & $3.87(1.78)$ & $8.74(3.44)$ \\
\hline Postherpetic neuropathy $(\mathrm{n}=355 \mathrm{I})$ & 60.1 & $65.21(14.94)$ & 53.34 & $1.03(1.63)$ & $6.42(3.45)$ \\
\hline Trigeminal neuralgia $(\mathrm{n}=3869)$ & 68.29 & $59.17(15)$ & 35.64 & $0.78(I .4 I)$ & $6.11(3.32)$ \\
\hline HIV-associated pain $(n=37 I)$ & 48.52 & $44.3(9.19)$ & 0.27 & $7.04(2.15)$ & $6.09(3.33)$ \\
\hline Multiple sclerosis-associated pain $(n=647)$ & 81.3 & $48.49(11.45)$ & 5.26 & $0.8 \mathrm{I}(\mathrm{I} .43)$ & $5.81(3.26)$ \\
\hline Stroke-associated pain $(\mathrm{n}=3087)$ & 58.47 & $65.32(15.74)$ & 52.22 & $2.65(2.04)$ & $7.17(3.57)$ \\
\hline Lumbar radiculopathy $(\mathrm{n}=56,358)$ & 56.82 & $53.97(14.38)$ & 21.71 & $0.68(1.3)$ & $5.74(3.3)$ \\
\hline Complex regional pain syndrome $(n=1808)$ & 72.23 & $50.27(12.84)$ & 10.51 & $0.72(1.28)$ & $5.79(3.27)$ \\
\hline Spinal cord injury $(n=33 \mathrm{I})$ & 48.34 & $51.91(17.21)$ & 20.54 & I.I (I.7I) & $6.09(3.64)$ \\
\hline Surgically-induced pain $(n=1478)$ & 60.69 & $48.75(16.17)$ & 18.34 & $1.04(1.95)$ & $5.24(3.13)$ \\
\hline Phantom limb pain $(n=205)$ & 28.78 & $56.43(14.05)$ & 28.29 & $1.9(2.35)$ & $7.02(3.69)$ \\
\hline Cervical radiculopathy $(n=40,844)$ & 58.57 & $50.36(12.48)$ & 11.09 & $0.5(1.09)$ & $5.12(3.02)$ \\
\hline Fibromyalgia $(n=75,570)$ & 70.07 & $50.44(13.52)$ & 12.32 & $0.61(1.2)$ & $5.36(3.15)$ \\
\hline Osteoarthritis $(n=365,086)$ & 60.53 & $61.85(13.39)$ & 39.45 & $0.88(1.45)$ & $6.05(3.34)$ \\
\hline Low back pain $(n=424,410)$ & 58.03 & $51.64(15.79)$ & 19.53 & $0.65(1.32)$ & $5.44(3.22)$ \\
\hline Migraine $(n=92,943)$ & 81.19 & $42.9(12.78)$ & 4.25 & $0.37(0.92)$ & $4.75(2.85)$ \\
\hline Rheumatoid arthritis $(n=40,362)$ & 72.75 & $57.88(13.6)$ & 29.26 & $1.71(1.31)$ & $6.96(3.5)$ \\
\hline Ankylosing spondylitis $(n=10,050)$ & 60.73 & $52.74(14.82)$ & 19.6 & $0.63(1.24)$ & $5.54(3.21)$ \\
\hline Psoriatic arthropathy $(n=4795)$ & 49.49 & $52.22(12.19)$ & $|3.5|$ & $0.7(1.16)$ & $6.53(3.38)$ \\
\hline Cancer pain $(n=28)$ & 50 & $53.07(15.37)$ & 17.86 & $6.07(3.67)$ & $7.11(3.98)$ \\
\hline Irritable bowel syndrome $(n=40,025)$ & 75.2 & $49.49(15.51)$ & $|5.7|$ & $0.47(1.07)$ & $4.84(2.89)$ \\
\hline Painful bladder syndrome $(\mathrm{n}=2870)$ & 98.29 & $44.28(14.5)$ & 8.08 & $0.44(1.07)$ & $4.63(2.75)$ \\
\hline Interstitial cystitis $(n=5662)$ & 88.2 & $50.98(15.25)$ & 18.32 & $0.55(1.14)$ & $5.08(2.95)$ \\
\hline
\end{tabular}

Notes: a $\mathrm{CCl}$ is a weighted composite measure that considers the presence of 16 diagnoses present in claims data; ${ }^{\mathrm{b}} \mathrm{CDS}$ is a weighted composite score derived from the presence of drug claim for specific medication classes.

Abbreviations: HIV, human immunodeficiency virus; CCl, Charlson Comorbidity Index; CDS, Chronic Disease Score; SD, standard deviation.

pain, and cancer pain cohorts were among those with the highest severity scores.

\section{Comorbid pain conditions}

Patients in this sample tended to have more than one concurrent painful condition. Of the 23 pain condition cohorts, the mean number of pain conditions claimed during the study period ranged from 1.39 (migraine, cancer pain) to 2.65 (multiple sclerosis-associated pain), as shown in Table 3. Overall conditions related to neuropathic pain tended to have the highest mean number of pain-related comorbidities, ie, multiple sclerosis pain (2.65), spinal cord injury (2.58), and HIV-associated pain (2.50).

Table 3 presents the percentage of patients within each pain cohort with a claim for another pain category or condition. Analogous with the prevalence rates of the pain categories and condition cohorts, comorbidity rates for each of the 23 pain condition cohorts were highest for the musculoskeletal category (including low back pain, osteoarthritis, and fibromyalgia) followed by the neuropathic pain category (led by stroke pain and radiculopathy conditions). Cancer pain and phantom limb pain were the least frequently reported pain comorbidities.

\section{Comorbid mental health and sleep disorders}

The presence of mental health and sleep comorbidities were described using multiple indicators, including percentage of patients with any mental health condition, mean number of mental health conditions, and percentage of patients with major depressive disorder, other depressive symptoms, anxiety, and other psychiatric conditions (Table 4). Rates of mental health comorbidities were also assessed across pain condition cohorts. The results indicate that pain conditions are comorbid with mental health conditions, but it should not be interpreted that this comorbidity means that there is a causal association between pain and mental health conditions. In general, HIV-associated pain and multiple sclerosisassociated pain were consistently among the pain conditions with the highest rates of mental health comorbidities. Other conditions with high rates included cancer pain, spinal cord injury, stroke-associated pain, and phantom limb pain.

The three pain conditions with the highest number of mental health comorbidities were HIV-associated pain (42.59\%), phantom limb (36.10\%), and multiple sclerosisassociated pain $(34.78 \%)$. The conditions with the lowest 


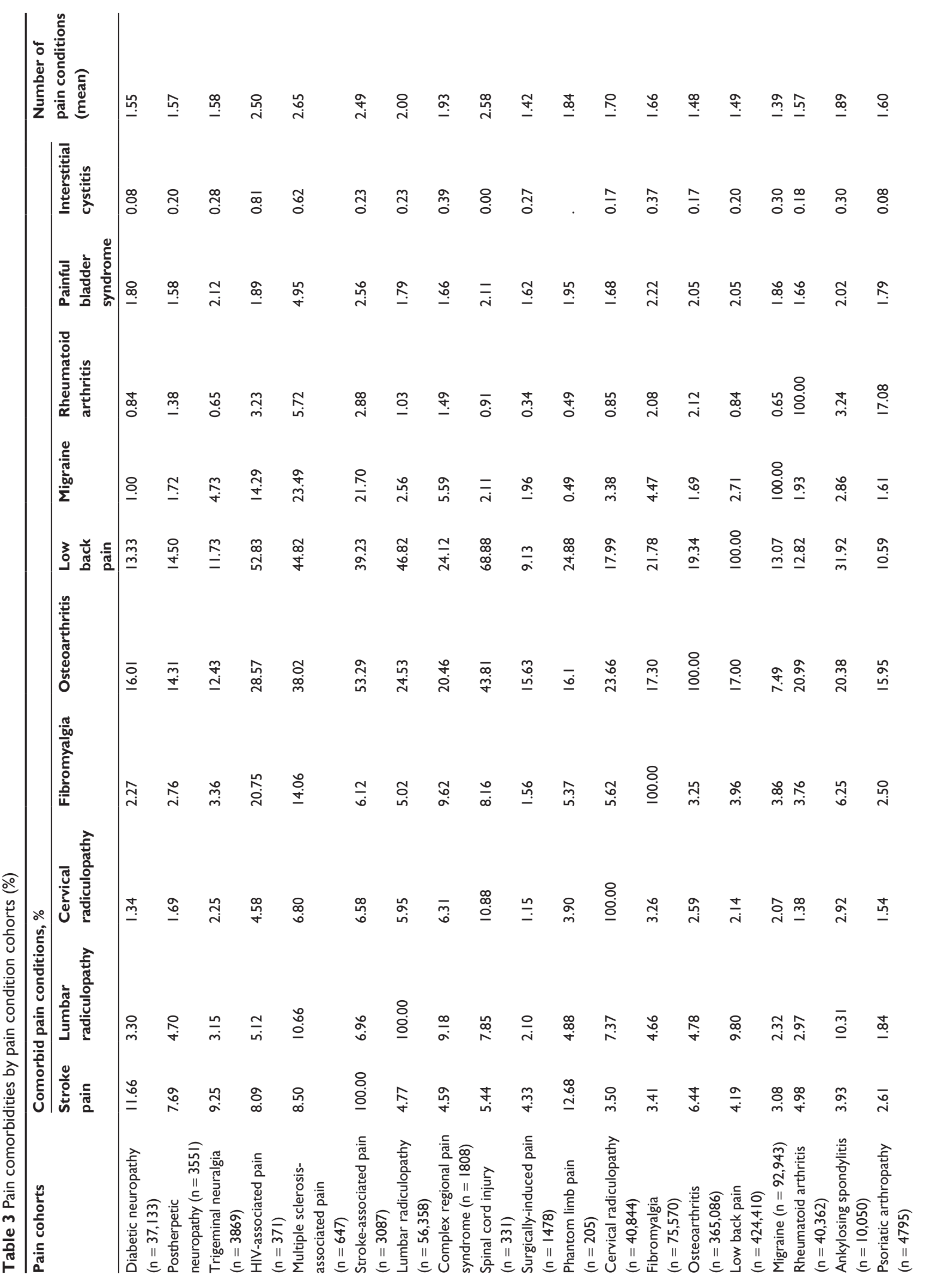




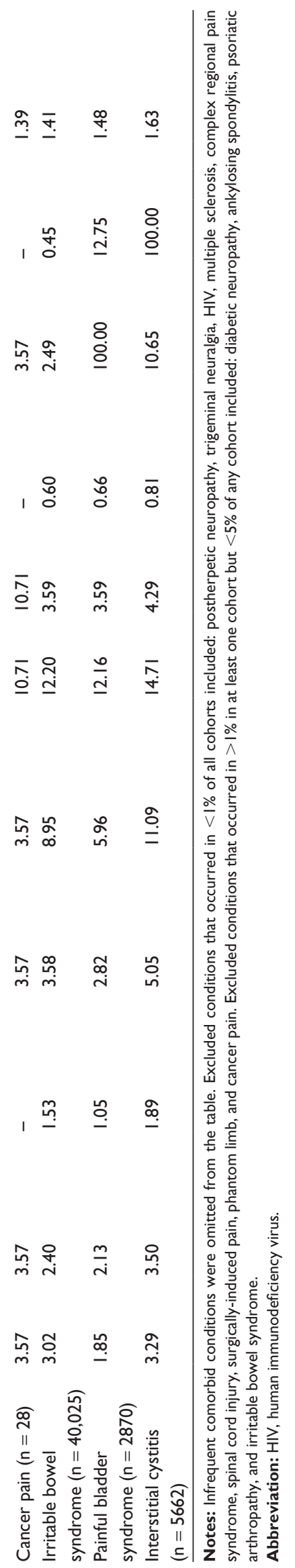

percentage having at least one comorbid mental health condition were found for postherpetic neuralgia (14.81\%), psoriatic arthropathy (13.31\%), and rheumatoid arthritis $(12.73 \%)$. The conditions with the highest mean number of mental health comorbidities were HIV-associated pain (1.82) and multiple sclerosis-associated pain (1.71). The conditions with the lowest mean number of mental health comorbidities were rheumatoid arthritis (1.32) and psoriatic arthropathy (1.30).

The condition with the greatest percentage of patients who had major depressive disorder was the HIV-associated pain cohort $(14.02 \%)$, while the lowest percentage was observed in the postherpetic neuralgia group (2.99\%). "Other depressive symptoms" was also highest in the HIV-associated pain group (21.02\%), while the lowest percentage was found in the rheumatoid arthritis cohort (2.81\%). Other psychiatric disorders, excluding depression and anxiety, were highest in stroke-associated pain patients (18.21\%) and lowest for psoriatic arthropathy patients $(2.82 \%)$. Anxiety had the greatest prevalence in the multiple sclerosis-associated pain cohort $(12.83 \%)$ and was lowest in the rheumatoid arthritis cohort (3.59\%).

The percentage of patients with sleep disorders ranged from $5.47 \%$ in the painful bladder symptom cohort to $11.59 \%$ in the multiple sclerosis-associated pain cohort, as shown in Table 4.

\section{Pain medications}

Most patients with pain were prescribed at least one pain pharmacotherapy during the one-year study period, with a minimum of $70.46 \%$ (in the irritable bowel syndrome cohort) of patients across the cohorts being prescribed at least one pharmacotherapy (Table 5). The median length of therapy was much more diverse across pain categories, with the shortest duration of therapy occurring among the surgically-induced pain cohort (41 days) and several groups with supplies lasting all 365 days, including cohorts with HIV-associated pain, multiple sclerosis-associated pain, complex regional pain syndrome, phantom limb pain, and cancer pain.

Across the 23 pain conditions, variability in prescribed pain medications was observed. The cohort with the largest percentage of patients taking at least one pharmacotherapy was phantom limb pain $(92.2 \%)$. The number of unique medications prescribed was examined across the cohorts. The cancer pain cohort was prescribed the greatest mean number of unique medications $(5.36 \pm 2.75)$, while psoriatic arthropathy was prescribed the lowest mean number 


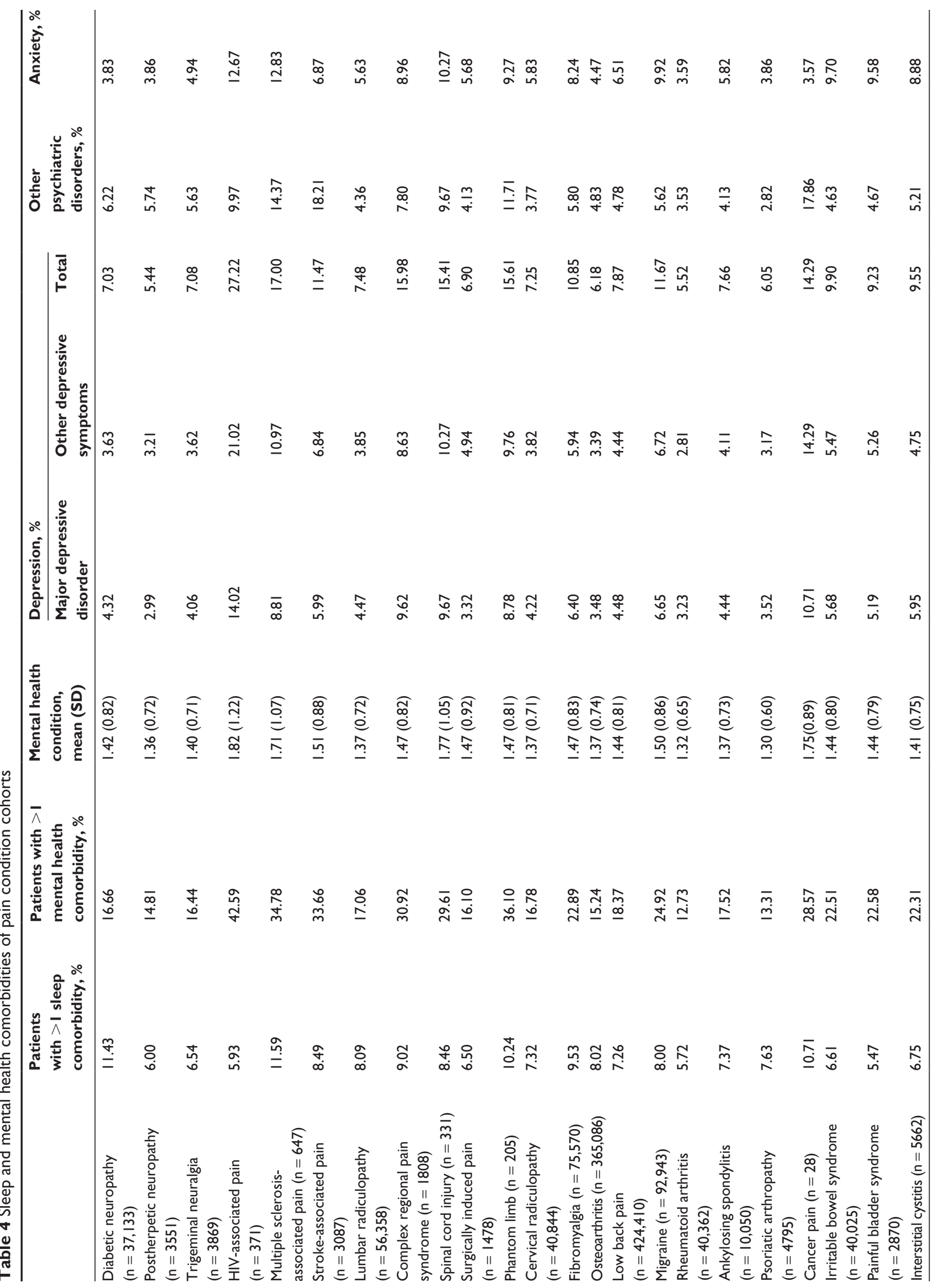


of unique medications $(2.76 \pm 2.06)$. Opioid medications, primarily strong opioids, were the most common medication used for all pain conditions, except for trigeminal neuralgia where anticonvulsants were used more frequently. The second most prescribed drug was antidepressants for all three visceral pain conditions (irritable bowel syndrome, painful bladder symptoms, and interstitial cystitis), cancer pain, migraine, and fibromyalgia and nonsteroidal anti-inflammatory drugs for all inflammatory arthritis conditions (rheumatoid arthritis, ankylosing spondylitis, and psoriatic arthropathy), osteoarthritis, and low back pain. The second most prescribed medication varied across neuropathic pain conditions, with antidepressants prescribed more often for diabetic neuropathy, HIV-associated pain, multiple sclerosis-associated pain, stroke-associated pain, and complex regional pain syndrome. Nonsteroidal anti-inflammatory drugs were more often prescribed for lumbar and cervical radiculopathies, spinal cord injury, and surgically-induced pain. Anticonvulsants were more often prescribed for postherpetic neuralgia, trigeminal neuralgia, and phantom limb pain.

We also assessed what type of medication was prescribed first following the index pain diagnosis. Across all 23 pain cohorts, the therapies most commonly prescribed as firstline were anticonvulsants/antiepileptics, antidepressants, nonsteroidal anti-inflammatory drugs, and strong opioids. Again, opioids were most commonly the first-line therapy for patients, including the majority of neuropathic pain condition cohorts (HIV-associated pain, multiple sclerosis-associated pain, stroke pain, lumbar and cervical radiculopathy, complex regional pain syndrome, spinal cord injury, surgicallyinduced pain, phantom limb pain), and cancer pain, as well as painful bladder symptoms, interstitial cystitis, osteoarthritis, low back pain, and ankylosing spondylitis. Antidepressants were first-line for cohorts with diabetic neuropathy, fibromyalgia, migraine, and irritable bowel syndrome. Nonsteroidal anti-inflammatory drugs were first-line for cohorts with rheumatoid arthritis and psoriatic arthropathy. Anticonvulsants were first-line for cohorts with postherpetic neuralgia and trigeminal neuralgia.

\section{Annual medical and drug costs}

Costs were examined by looking at total median annual health care costs, including inpatient, outpatient, pharmaceutical, and emergency room costs (Figure 1). These cost components were further examined by looking at costs incurred in conjunction with pain diagnosis-related services, and costs in the absence of a pain diagnosis. Pain-related costs were defined as costs that were coded for any pain condition as listed in Table 1. Therefore, pain costs presented in Figure 2 are not necessarily related to the primary diagnosed condition, and could reflect the cost of a comorbid pain condition. Consistently, cancer pain most commonly had the highest costs across the cost components examined. The cohorts with the lowest costs were less consistent across the cost components and most commonly included the postherpetic neuralgia, migraine, surgically-induced pain, and irritable bowel syndrome cohorts.

Overall, the highest median total costs were found in cancer pain $(\$ 56,404.15)$. The cancer pain cohort also had the highest total median inpatient $(\$ 25,530.43)$, outpatient $(\$ 20,363.26)$, and emergency room $(\$ 1,436.96)$ costs. However, the HIVassociated pain cohort had the highest median total pharmaceutical costs $(\$ 13,276.81)$. The migraine cohort had the lowest overall total median costs $(\$ 4855.38)$, as well as the lowest total outpatient median costs (\$2102.30). The cohort with the lowest total inpatient costs (\$7584.18) and total emergency room costs $(\$ 416.45)$ was the postherpetic neuralgia cohort. The lowest median pharmaceutical costs were observed in the surgically-induced pain cohort (\$967.16).

When examining pain-related cost components, the multiple sclerosis-associated pain cohort had the highest costs for both pain-related total costs $(\$ 4011.12)$ and pain-related outpatient costs $(\$ 3030.45)$. Irritable bowel syndrome had the lowest total pain-related (\$151.28) and outpatient painrelated costs (\$143.81). Inpatient pain-related costs were highest for HIV-associated pain patients $(\$ 11,862.32)$ and lowest for surgically-induced pain patients (\$218.54). The cancer pain cohort had the highest costs across all the nonpain-related cost components (total \$42,673.92), ie, inpatient $(\$ 25,148.90)$, outpatient $(\$ 18,993.56)$, and emergency room (\$1234.27) costs. However, the lowest nonpain-related costs were varied across the pain conditions. The lowest total nonpain-related costs were observed in psoriatic arthropathy (\$1867.16). The multiple sclerosis associated-pain cohort had the lowest inpatient nonpain-related costs (\$4613.97). HIVassociated pain had the lowest outpatient nonpain-related costs (\$1674.09). The postherpetic neuralgia cohort had the lowest emergency room nonpain-related costs (\$374.35).

\section{Discussion}

The objectives of this study were to characterize the rates of comorbidity, pain medication use, and health care costs for selected pain conditions. This analysis illustrates the high levels of comorbidities faced by patients with pain. Rates of comorbid conditions related to pain, mental health, and sleep-related disorders are shown for the 23 conditions from 
Table 5 Pain medication use by selected pain condition cohorts

\begin{tabular}{|c|c|c|c|c|c|c|c|c|c|}
\hline & $\begin{array}{l}\text { Patients } \\
\text { taking } \geq \text { I } \\
\text { pharmacotherapy } \\
\text { (\%) }\end{array}$ & $\begin{array}{l}\text { Unique } \\
\text { drugs, \% } \\
\text { (Mean, } \\
\text { SD) }\end{array}$ & $\begin{array}{l}\text { Length of } \\
\text { therapy } \\
\text { (median } \\
\text { days) }\end{array}$ & $\begin{array}{l}\text { Analgesics/ } \\
\text { antipyretics, } \\
\text { NEC }^{a}\end{array}$ & $\begin{array}{l}\text { Anticonvulsants/ } \\
\text { Antiepileptics }\end{array}$ & SNR ${ }^{\mathbf{l b}}$ & SSRIc & TCAs $^{d}$ & $\begin{array}{l}\text { Other } \\
\text { antidepressants }\end{array}$ \\
\hline $\begin{array}{l}\text { Diabetic } \\
\text { neuropathy } \\
(n=37,133)\end{array}$ & 74.00 & $\begin{array}{l}3.13 \\
(2.33)\end{array}$ & 297.00 & 1.08 & 25.21 & 8.13 & 18.40 & 10.55 & 7.10 \\
\hline $\begin{array}{l}\text { Postherpetic } \\
\text { neuropathy } \\
(\mathrm{n}=355 \mathrm{I})\end{array}$ & 84.15 & $\begin{array}{l}3.33 \\
(2.37)\end{array}$ & 245.50 & 1.04 & $51.25^{*}$ & 8.65 & 15.46 & $|5.9|$ & 5.32 \\
\hline $\begin{array}{l}\text { Trigeminal } \\
\text { neuralgia } \\
(\mathrm{n}=3869)\end{array}$ & 87.59 & $3(2)$ & 300.00 & 2.04 & $61.00 *$ & 8.12 & 16.85 & 10.75 & 6.36 \\
\hline $\begin{array}{l}\text { HIV-associated } \\
\text { pain }(n=37 I)\end{array}$ & 86.79 & $\begin{array}{l}5.08 \\
(3.26)\end{array}$ & 376.00 & 5.39 & 21.29 & 9.70 & 28.57 & 20.49 & 20.49 \\
\hline $\begin{array}{l}\text { Multiple } \\
\text { sclerosis- } \\
\text { associated } \\
\text { pain }(n=647)\end{array}$ & 86.71 & $\begin{array}{l}4.73 \\
(3.31)\end{array}$ & 480.00 & 3.09 & 37.25 & 19.01 & 32.77 & 16.54 & 15.92 \\
\hline $\begin{array}{l}\text { Stroke- } \\
\text { associated } \\
\text { pain }(n=3087)\end{array}$ & 81.18 & $\begin{array}{l}3.48 \\
(2.55)\end{array}$ & 270.00 & 4.18 & 18.37 & 8.71 & 26.89 & 9.62 & 7.97 \\
\hline $\begin{array}{l}\text { Lumbar } \\
\text { radiculopathy } \\
(\mathrm{n}=56,358)\end{array}$ & 79.22 & $\begin{array}{l}3.76 \\
(2.76)\end{array}$ & 240.00 & 1.64 & 18.86 & 7.79 & 17.69 & 7.59 & 7.95 \\
\hline $\begin{array}{l}\text { Complex } \\
\text { regional pain } \\
\text { syndrome } \\
(\mathrm{n}=1808)\end{array}$ & 90.65 & $\begin{array}{l}5.00 \\
(2.98)\end{array}$ & 632.00 & 2.38 & 48.56 & 20.24 & 25.72 & 21.57 & 16.65 \\
\hline $\begin{array}{l}\text { Spinal cord } \\
\text { injury }(n=33 \mathrm{I})\end{array}$ & 86.71 & $\begin{array}{l}4.14 \\
(2.80)\end{array}$ & 215.00 & 0.91 & 23.26 & 12.39 & 19.34 & 7.55 & 11.48 \\
\hline $\begin{array}{l}\text { Surgically } \\
\text { induced pain } \\
(n=1478)\end{array}$ & 90.26 & $\begin{array}{l}2.99 \\
(2.23)\end{array}$ & 41.00 & 1.89 & 5.48 & 4.74 & 15.63 & 3.52 & 5.21 \\
\hline $\begin{array}{l}\text { Phantom limb } \\
(n=205)\end{array}$ & 92.20 & $\begin{array}{l}5.05 \\
(3.17)\end{array}$ & 720.00 & 0.49 & 60.49 & 19.51 & 19.02 & 23.41 & 11.71 \\
\hline $\begin{array}{l}\text { Cervical } \\
\text { radiculopathy } \\
(n=40,844)\end{array}$ & 74.94 & $\begin{array}{l}3.48 \\
(2.57)\end{array}$ & 157.00 & 2.00 & 13.45 & 6.67 & 17.14 & 6.04 & 7.79 \\
\hline $\begin{array}{l}\text { Fibromyalgia } \\
(n=75,570)\end{array}$ & 77.28 & $\begin{array}{l}3.81 \\
(2.83)\end{array}$ & 273.00 & 2.46 & 13.33 & 12.29 & 21.71 & 10.40 & 11.52 \\
\hline $\begin{array}{l}\text { Osteoarthritis } \\
(n=365,086)\end{array}$ & 79.91 & $\begin{array}{l}3.19 \\
(2.30)\end{array}$ & 226.00 & 1.35 & 9.47 & 5.68 & 17.16 & 5.92 & 6.65 \\
\hline $\begin{array}{l}\text { Low back pain } \\
(\mathrm{n}=424,410)\end{array}$ & 79.32 & $\begin{array}{l}3.54 \\
(2.57)\end{array}$ & 150.00 & I.77 & 10.67 & 6.43 & 17.52 & 6.11 & 7.65 \\
\hline $\begin{array}{l}\text { Migraine } \\
(\mathrm{n}=92,943)\end{array}$ & 80.09 & $\begin{array}{l}3.71 \\
(2.91)\end{array}$ & 229 & 9.77 & 22.28 & 9.86 & 23.22 & 14.01 & 10.76 \\
\hline $\begin{array}{l}\text { Rheumatoid } \\
\text { arthritis } \\
(\mathrm{n}=40,362)\end{array}$ & 79.73 & $\begin{array}{l}2.98 \\
(2.22)\end{array}$ & 410 & 1.34 & 8.54 & 5.79 & 16.72 & 6.58 & 6.53 \\
\hline $\begin{array}{l}\text { Ankylosing } \\
\text { spondylitis } \\
(\mathrm{n}=10,050)\end{array}$ & 78.44 & $\begin{array}{l}3.51 \\
(2.58)\end{array}$ & 267.00 & 1.60 & 10.92 & 7.70 & 18.09 & 6.72 & 8.32 \\
\hline $\begin{array}{l}\text { Psoriatic } \\
\text { arthropathy } \\
(\mathrm{n}=4795)\end{array}$ & 75.60 & $\begin{array}{l}2.76 \\
(2.06)\end{array}$ & 287.00 & 0.92 & 6.19 & 5.86 & 16.96 & 5.15 & 7.74 \\
\hline $\begin{array}{l}\text { Cancer pain } \\
(\mathrm{n}=28)\end{array}$ & 78.57 & $\begin{array}{l}5.36 \\
(2.75)\end{array}$ & 399.5 & 7.14 & 28.57 & 7.14 & 28.57 & 17.86 & 21.43 \\
\hline
\end{tabular}




\begin{tabular}{|c|c|c|c|c|c|c|c|c|c|}
\hline $\begin{array}{l}\text { Total } \\
\text { antidepressants }\end{array}$ & $\begin{array}{l}\text { Anxiolytics/ } \\
\text { sedatives/ } \\
\text { hypnotics } \\
\text { NEC }\end{array}$ & Benzodiazepines & $\begin{array}{l}\text { COX-2e } \\
\text { inhibitors }\end{array}$ & $\begin{array}{l}\text { Muscle } \\
\text { Relaxants }\end{array}$ & NSAIDs ${ }^{f}$ & $\begin{array}{l}\text { Strong } \\
\text { opioids }\end{array}$ & $\begin{array}{l}\text { Total } \\
\text { weak } \\
\text { opioids }\end{array}$ & $\begin{array}{l}\text { Total opioid } \\
\text { use (weak } \\
\text { and strong) }\end{array}$ & Triptans \\
\hline $34.26 *$ & 12.68 & 18.62 & 4.11 & 10.53 & 24.29 & 37.60 & 18.55 & 46.30 & 0.06 \\
\hline 36.19 & 15.49 & 20.61 & 4.90 & 9.55 & 20.05 & 46.66 & 20.36 & 55.53 & 0.34 \\
\hline 33.37 & 13.62 & 23.47 & 3.75 & 12.72 & 24.86 & 43.24 & 18.04 & 50.87 & 0.65 \\
\hline 50.13 & 28.84 & 29.38 & 2.96 & 20.75 & 51.48 & $66.3 I^{*}$ & 23.99 & 69.54 & 0.81 \\
\hline $57.50 *$ & 23.49 & 37.56 & 3.71 & 31.07 & 29.52 & 49.30 & 26.28 & 58.89 & 1.85 \\
\hline $41.04^{*}$ & 17.30 & 28.02 & 5.96 & $|5.8|$ & 24.81 & $42.92 *$ & 25.53 & 54.84 & 0.65 \\
\hline 31.14 & 14.95 & 23.99 & 6.94 & 27.53 & 34.67 & $50.12 *$ & 22.61 & 58.51 & 0.38 \\
\hline 56.86 & 23.34 & 35.90 & 6.03 & 26.16 & 30.97 & $69.58^{*}$ & 23.51 & 76.38 & 0.55 \\
\hline 35.95 & 18.43 & 28.40 & 3.93 & 32.02 & 36.86 & $64.35^{*}$ & 23.87 & 71.00 & 0.30 \\
\hline 23.00 & 15.70 & 16.31 & 5.07 & 10.15 & 32.81 & $79.57^{*}$ & 20.91 & 84.44 & 0.14 \\
\hline 51.22 & 25.37 & 33.17 & 2.44 & 20.49 & 28.29 & $80.00 *$ & 20.00 & 82.93 & - \\
\hline 29.09 & 13.88 & 21.47 & 5.32 & 26.77 & 33.77 & $43.35^{*}$ & 18.24 & 50.51 & 0.56 \\
\hline $39.71 *$ & $|7.8|$ & 24.87 & 5.38 & 27.95 & 34.34 & 40.03 & 21.33 & 49.52 & 0.64 \\
\hline 27.89 & |4.1I & 20.19 & 10.21 & 15.49 & 38.10 & $45.23^{*}$ & 23.70 & 55.48 & 0.26 \\
\hline 28.78 & 13.44 & 21.89 & 5.31 & 33.11 & 38.09 & $47.24 *$ & 21.50 & 55.84 & 0.36 \\
\hline $42.33^{*}$ & 16.43 & 23.77 & 2.57 & 19.87 & 31.55 & 41.93 & 17.35 & 48.28 & 6.33 \\
\hline 28.16 & 13.54 & 17.50 & 11.54 & 13.94 & $40.24 *$ & 38.05 & 22.95 & 49.7I & 0.33 \\
\hline 30.84 & $|5.0|$ & 21.82 & 7.99 & 25.17 & 39.84 & $42.77^{*}$ & 21.85 & 52.35 & 0.50 \\
\hline 27.90 & 12.49 & 15.45 & 9.47 & 12.05 & $40.77^{*}$ & 32.30 & 16.89 & 41.42 & 0.17 \\
\hline 46.43 & 21.43 & 28.57 & 3.57 & 14.29 & 14.29 & $67.86 *$ & 25.00 & 71.43 & 3.57 \\
\hline
\end{tabular}


Table 5 (Continued)

\begin{tabular}{|c|c|c|c|c|c|c|c|c|c|}
\hline & $\begin{array}{l}\text { Patients } \\
\text { taking } \geq \mathbf{I} \\
\text { pharmacotherapy } \\
\text { (\%) }\end{array}$ & $\begin{array}{l}\text { Unique } \\
\text { drugs, \% } \\
\text { (Mean, } \\
\text { SD) }\end{array}$ & $\begin{array}{l}\text { Length of } \\
\text { therapy } \\
\text { (median } \\
\text { days) }\end{array}$ & $\begin{array}{l}\text { Analgesics/ } \\
\text { antipyretics, } \\
\text { NEC }^{\text {a }}\end{array}$ & $\begin{array}{l}\text { Anticonvulsants/ } \\
\text { Antiepileptics }\end{array}$ & SNR ${ }^{\mathbf{I b}^{\mathrm{b}}}$ & $\mathbf{S S R I}^{\mathrm{c}}$ & $T^{\prime C A s}{ }^{d}$ & $\begin{array}{l}\text { Other } \\
\text { antidepressants }\end{array}$ \\
\hline $\begin{array}{l}\text { Irritable bowel } \\
\text { syndrome } \\
(n=40,025)\end{array}$ & 70.46 & $\begin{array}{l}2.98 \\
(2.30)\end{array}$ & 188.00 & 2.30 & 6.27 & 7.33 & 22.85 & 9.47 & 9.14 \\
\hline $\begin{array}{l}\text { Painful bladder } \\
\text { syndrome } \\
(n=2870)\end{array}$ & 76.10 & $\begin{array}{l}3.17 \\
(2.40)\end{array}$ & 95.00 & 2.40 & 6.17 & 6.76 & 20.52 & 8.68 & 8.57 \\
\hline $\begin{array}{l}\text { Interstitial } \\
\text { cystitis } \\
(n=5662)\end{array}$ & 80.36 & $\begin{array}{l}3.59 \\
(2.70)\end{array}$ & 270.00 & 2.17 & 11.20 & 8.85 & 20.24 & 21.25 & 9.64 \\
\hline
\end{tabular}

a large health plan using administrative health claims data. The findings of this study are consistent with previous literature that aims to characterize rates of comorbid conditions. Conditions do often occur together, whether they are physical, painful, or mental. Most patients tend to have more than one pain condition, so the term "chronic pain" should be used with caution because conditions do tend to vary across patient populations and treatment patterns.

Understanding the rate of comorbidity for specific pain conditions may aid in the interpretation of study findings that lack distinct classification of "chronic pain" or that exclude subjects who have comorbid conditions in an effort to reduce bias and confounding. These findings may be used as a resource for clinical and research fields to understand the variability among patients who experience pain. According to the International Pain Society, pain management is inadequate in most of the world because: there are major deficits in knowledge on the part of health care professionals regarding the mechanisms and management of pain; there is inadequate access to treatment and failure to recognize the necessity for access to management akin to other chronic diseases such as diabetes or chronic heart disease; most countries have no national policy at all or very inadequate policies regarding management of pain as a health problem, including an inadequate level of research and education; and pain medicine is not recognized as a distinct specialty with a unique body of knowledge and defined scope of practice founded on research and comprehensive training programs. ${ }^{21}$ The Institute of Medicine has called for a cultural transformation regarding pain care. ${ }^{2}$ In order to achieve this transformation, the Institute of Medicine plan requests development of a national population-based prevention/management strategy, a more tailored approach to treatment, and a strategy to reduce or remove the barriers which limit access to care. ${ }^{2}$

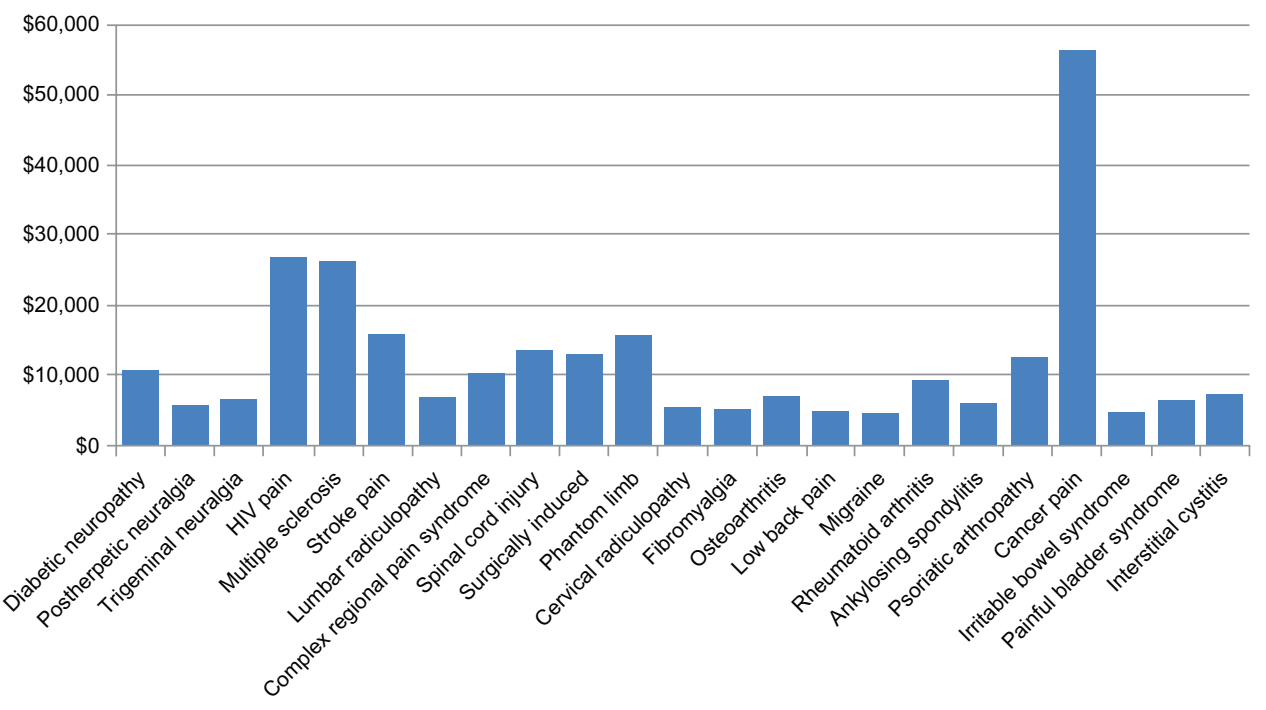

Figure I Total annual median costs for all medical and drug use by pain condition cohorts. 


\begin{tabular}{|c|c|c|c|c|c|c|c|c|c|}
\hline $\begin{array}{l}\text { Total } \\
\text { antidepressants }\end{array}$ & $\begin{array}{l}\text { Anxiolytics/ } \\
\text { sedatives/ } \\
\text { hypnotics } \\
\text { NEC }\end{array}$ & Benzodiazepines & $\begin{array}{l}\text { COX-2 } \\
\text { inhibitors }\end{array}$ & $\begin{array}{l}\text { Muscle } \\
\text { Relaxants }\end{array}$ & NSAIDs $^{f}$ & $\begin{array}{l}\text { Strong } \\
\text { opioids }\end{array}$ & $\begin{array}{l}\text { Total } \\
\text { weak } \\
\text { opioids }\end{array}$ & $\begin{array}{l}\text { Total opioid } \\
\text { use (weak } \\
\text { and strong) }\end{array}$ & Triptans \\
\hline $37.32 *$ & 14.86 & 25.04 & 3.22 & 12.65 & 22.48 & 30.30 & 14.27 & 37.34 & 0.50 \\
\hline 34.60 & 16.24 & 21.57 & 2.47 & 12.16 & 32.54 & $44.15^{*}$ & 18.40 & 51.43 & 0.73 \\
\hline $44.68^{*}$ & 28.12 & 27.18 & 4.24 & $|5.6|$ & 26.09 & 43.24 & 22.18 & 51.94 & 0.67 \\
\hline
\end{tabular}

Note: *Most common therapy prescribed as first-line for cohort.

Abbreviations: A, not elsewhere classified; B, serotonin norepinephrine reuptake inhibitors; C, selective serotonin reuptake inhibitors; D, tricyclic antidepressants; E, cyclooxygenase; F, nonsteroidal anti-inflammatory drugs; HIV, human immunodeficiency virus; SD, standard deviation.

The cohort with the highest mean number of comorbid pain conditions was in the multiple sclerosis-associated pain (2.65) cohort, while the lowest mean number of comorbid pain conditions was observed in the cancer pain and migraine cohorts (1.39). Thus, multiple sclerosis has a higher comorbidity with other pain conditions when compared with cancer pain and migraine.

There was a large sample size available for use in the current study from the MarketScan database. This reaffirms that pain conditions and comorbid mental health conditions are quite prominent in this population, and more research should be done to enhance treatment and understanding, particularly in the comorbid patient, because this study showed a range of mean comorbid pain conditions of 1.39-2.65.

Almost all patients in the sample were taking a pain medication and many were taking more than one type of pain medication, while the type of medications prescribed across the cohorts varied. Surprisingly, opioid medication use was consistently prescribed first in the claims data across all pain conditions. The average number of unique medications was $3.53 \pm 2.58$ across the sample. These findings suggest that these conditions (and their comorbidities) are a high burden to patients. The burden to the patients exists in both suffering from painful conditions, but also in having to take several medications to manage the pain.

The study demonstrates that the majority of the 23 pain conditions affect women more frequently, which is consistent with previous pain studies. However, this study found that there were notable differences across the disease states. Also in line with previously published studies, pain conditions usually affect those in the middle-aged and older groups, but again differences were found in selected pain states. ${ }^{4}$ Older patients generally are more likely to experience pain as a result of diseases that are typically found in an older population, such as stroke. Again, costs were varied across the pain cohorts. Some cohorts had much higher costs than others. The cost components examined show the variety in pain-related costs and nonpain-related costs. The conditions

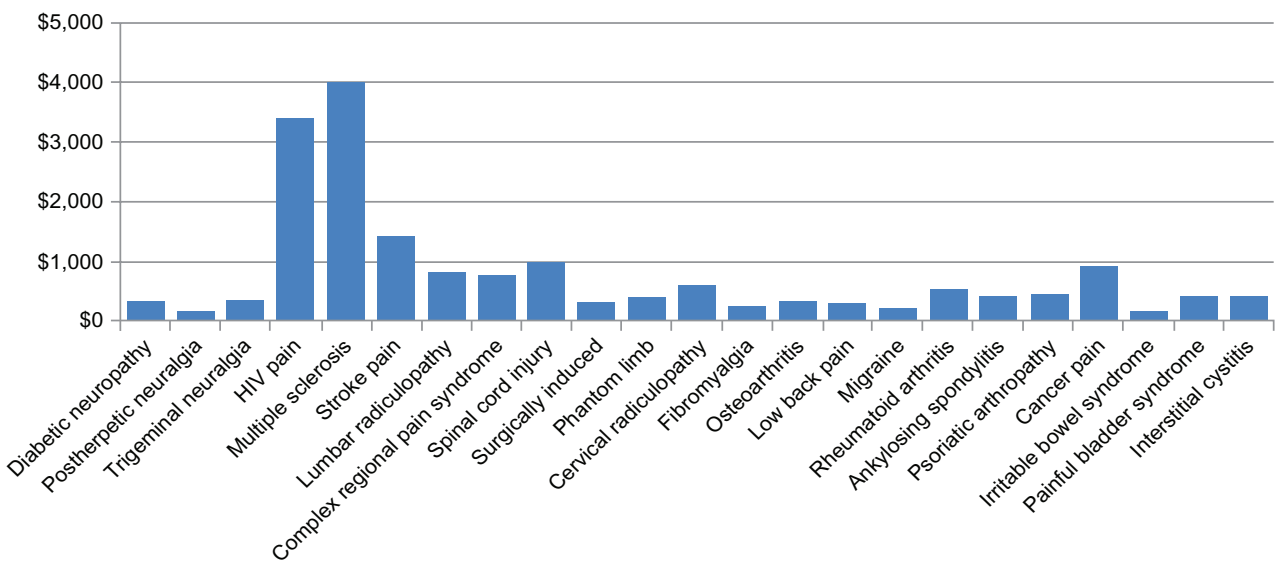

Figure 2 Annual median pain-related medical costs by pain condition cohorts. 
with the highest pain-related costs across the cost components examined (inpatient, outpatient, and emergency room) were multiple sclerosis-associated pain and HIV-associated pain. This finding suggests a large portion of health care dollars is used to treat the pain component of these debilitating illnesses. Across the pain conditions, approximately $20 \%$ of total visits were to an emergency room, thus increasing costs. Resource utilization in general and for pain could be avoided/reduced if the patient was being well managed pharmacologically by a primary care physician.

There are some limitations to using claims data, including difficulty generalizing to a noninsured population, miscoding due to administrative causes such as making a diagnosis fit a billing requirement or sometimes choosing the code that obtains the greater payment. ${ }^{22}$ Although many pain conditions are chronic, ICD-9 codes do not include the chronicity of the illness in the diagnosis. This study limited the scope of comorbidities to other pain, mental health, and sleep-related diagnoses. Other studies have found that other physical comorbidities, such as hypertension or heart disease, are commonly reported by patients with pain. If this had been examined, an even greater burden would be present, but this has been shown by previous literature. The patients were also put into categories somewhat arbitrarily if they had other pain comorbidities, as mentioned in the study sample and cohorts section. Further, there were so many comorbid patients that we could not determine whether costs/prescription medication use is driven by the primary diagnosis or one of the other diagnoses.

Claims data may also underrepresent mental health conditions. Data from 2005 indicate the 12-month prevalence of mental disorder to be $29.1 \%$ among US adults. ${ }^{23}$ In this sample, the prevalence of any mental health comorbidity was $18 \%$. Previous data have shown that at least $10 \%$ of the US population has a sleep disorder. ${ }^{24}$ In this sample, the prevalence of any sleep disorder was $7.7 \%$. Therefore, the comorbiditiy of pain and mental health may be even higher than what is reported in claims.

Pain conditions are often difficult to diagnose properly. This could potentially affect the dataset because one provider may have provided a different diagnosis than a second provider and this could be reflected as a comorbid condition. According to Dworkin et al, some physicians were coding only that a patient was seen for herpes zoster, when the patient may have also presented with postherpetic neuropathy. ${ }^{25}$ This could lead to an underestimate of the prevalence of pain conditions that are related to other health conditions in the population under study.
The majority of patients in this study were prescribed pain medications. This does not include any over the counter pain medications, medications purchased without use of insurance, or free samples provided by physicians. We were able to determine which pain conditions had the highest number of unique pain medications, as well as what medication classes were prescribed as first, second, and third in the insurance claims across the different conditions. According to a synthesis of the available literature on treatment of pain, the best practices for prescribing medications should be based on the type of pain, and each pain condition should be treated as unique. ${ }^{26}$ Our findings are consistent with those of Kroenke et al, ie, that patients are generally started on different first-line therapies based on the type of pain they are experiencing. ${ }^{26}$ According to the recent Institute of Medicine recommendations, treatment strategies should be tailored to each patient as opposed to following a standardized, stepped approach. ${ }^{2}$ Opioids were the first prescribed medication for the majority of the neuropathic pain cohorts. Nonsteroidal anti-inflammatory drugs were prescribed first-line for patients with rheumatoid arthritis and psoriatic arthropathy, although the guidance suggests nonsteroidal anti-inflammatory drugs should be prescribed first-line for most pain conditions. Prescription of antidepressants and anticonvulsants were generally consistent with the recommendations.

This study demonstrated how costly these pain conditions can be to treat. In the sample, there were high costs that varied across the pain cohorts. The cost analysis in this study provides information about the original illness causing the pain to occur. For example, cancer pain had the highest median costs overall. In this example, costs are likely driven by the costs of treating the cancer. Interestingly, some of the conditions that had the highest pain-related costs had the lowest nonpain-related costs, such as the multiple sclerosisassociated pain and HIV-associated pain cohorts. This finding suggests that a large portion of the cost to treat these patients is due to pain. Cancer pain had the highest emergency room pain-related costs (\$936.48), while osteoarthritis had the lowest emergency room pain-related costs $(\$ 180.57)$. This finding suggests that cancer pain is acute and severe, while osteoarthritis is chronic and does not generally result in an emergency room visit for treatment. While the current study looked at pain-related and nonpain-related cost components, further research could be done with respect to costs to determine what costs are incurred for treating the initial conditions and then examine what proportion of costs the comorbid conditions contribute to the overall costs. 
The comorbid patient continually presents a challenge to treating physicians. This research highlights the burden, incidence, and costs of pain in patients with comorbid conditions. The body of research on comorbidities continues to grow. Improving care for each patient by taking a holistic approach to their treatment that encompasses not only the pain condition the patient is currently presenting with, but also their mental health and other pain conditions, is a potential way to drive health care costs downward and ultimately improve outcomes.

\section{Disclosure}

The authors are employees of Eli Lilly and Company.

\section{References}

1. Zagari MJ, Mazonson PD, Longton WC. Pharmacoeconomics of chronic nonmalignant pain. Pharmacoeconomics. 1996;10(4):356-377.

2. Institute of Medicine. Relieving pain in America: a blueprint for transforming prevention, care, education, and research. Available from: http://www.iom.edu/ /media/Files/Report\%20Files/2011/RelievingPain-in-America-A-Blueprint-for-Transforming-Prevention-CareEducation-Research/Pain\%20Research\%202011\%20Report\%20Brief. pdf. Accessed August 26, 2011.

3. Stewart WF, Ricci JA, Chee E, Morganstein D, Lipton R. Lost productive time and cost due to common pain conditions in the US workforce. JAMA. 2003;290(18):2443-2454.

4. Gerdle B, Bjork J, Henriksson C, Bengtsson A. Prevalence of current and chronic pain and their influences upon work and health care-seeking: a population study. J Rheumatol. 2004;31(7):1399-1406.

5. Wolff JL, Starfield B, Anderson G. Prevalence, expenditures, and complications of multiple chronic conditions in the elderly. Arch Intern Med. 2002;162(20):2269-2276.

6. Bair MJ, Robinson RL, Eckert GJ, Stang PE, Croghan TW, Kroenke K. Impact of pain on depression treatment response in primary care. Psychosom Med. 2004;66(1):17-22.

7. Bair MJ, Robinson RL, Katon W, Kroenke K. Depression and pain comorbidity: a literature review. Arch Intern Med. 2003;163(20): 2433-2445.

8. Arnow BA, Hunkeler EM, Blasey CM, et al. Comorbid depression, chronic pain, and disability in primary care. Psychosom Med. 2006;68(2): 262-268.

9. Arnow BA, Blasey CM, Lee J, et al. Relationships among depression, chronic pain, chronic disabling pain, and medical costs. Psychiatr Serv. 2009;60(3):344-350.
10. Sareen J, Cox BJ, Clara I, Asmundson GJ. The relationship between anxiety disorders and physical disorders in the US National Comorbidity Survey. Depress Anxiety. 2005;21(4):193-202.

11. Bao Y, Sturm R, Croghan TW. A national study of the effect of chronic pain on the use of health care by depressed persons. Psychiatr Serv. 2003;54(5):693-697.

12. Gureje O, Von Korff M, Kola L, et al. The relation between multiple pains and mental disorders: results from the World Mental Health Surveys. Pain. 2008;135(1-2):82-91.

13. Craig A, Tran Y, Middleton J. Psychological morbidity and spinal cord injury: a systematic review. Spinal Cord. 2009;47(2):108-114.

14. Ohayon MM. Relationship between chronic painful physical condition and insomnia. J Psychiatr Res. 2005;39(2):151-159.

15. Butchart A, Kerr EA, Heisler M, Piette JD, Krein SL. Experience and management of chronic pain among patients with other complex chronic conditions. Clin J Pain. 2009;25(4):293-298.

16. van Dijk GM, Veenhof C, Schellevis F, et al. Comorbidity, limitations in activities and pain in patients with osteoarthritis of the hip or knee. BMC Musculoskelet Disord. 2008;9:95.

17. Nicholson B, Verma S. Comorbidities in chronic neuropathic pain. Pain Med. 2004;5(Suppl 1):S9-S27.

18. Woolf CJ. Central sensitization: uncovering the relation between pain and plasticity. Anesthesiology. 2007;106(4):864-867.

19. Scher AI, Stewart WF, Lipton RB. The comorbidity of headache with other pain syndromes. Headache. 2006;46(9):1416-1423.

20. Tietjen GE, Brandes JL, Peterlin BL, et al. Allodynia in migraine: association with comorbid pain conditions. Headache. 2009;49(9): 1333-1344.

21. International Association for the Study of Pain. Declaration of Montreal. Available from: http://www.iasp-pain.org/Content/NavigationMenu/ InternationalPainSummit/DeclarationofMontr233al/default.htm. Accessed August 26, 2011.

22. Riley GF. Administrative and claims records as sources of health care cost data. Med Care. 2009;47(7 Suppl 1):S51-S55.

23. Bijl RV, de Graaf R, Hiripi E, et al. The prevalence of treated and untreated mental disorders in five countries. Health Aff (Millwood). 2003;22(3):122-133.

24. Ram S, Seirawan H, Kumar SK, Clark GT. Prevalence and impact of sleep disorders and sleep habits in the United States. Sleep Breath. 2010;14(1):63-70.

25. Dworkin RH, Malone DC, Panarites CJ, Armstrong EP, Pham SV. Impact of postherpetic neuralgia and painful diabetic peripheral neuropathy on health care costs. J Pain. 2010;11(4):360-368.

26. Kroenke K, Krebs EE, Bair MJ. Pharmacotherapy of chronic pain: a synthesis of recommendations from systematic reviews. Gen Hosp Psychiatry. 2009;31(3):206-219.
Journal of Pain Research

\section{Publish your work in this journal}

The Journal of Pain Research is an international, peer-reviewed, open access, online journal that welcomes laboratory and clinical findings in the fields of pain research and the prevention and management of pain. Original research, reviews, symposium reports, hypothesis formation and commentaries are all considered for publication.

\section{Dovepress}

The manuscript management system is completely online and includes a very quick and fair peer-review system, which is all easy to use. Visit http://www.dovepress.com/testimonials.php to read real quotes from published authors. 